\title{
The budgetary impact of alemtuzumab in multiple sclerosis in Quito, Ecuador. Payer's perspective
}

\author{
Luis J. Pastor-Quirós ${ }^{1}$, Edgar P. Correa-Díaz ${ }^{2}$ \\ ${ }^{1}$ Independent Scholar, Heredia - Costa Rica \\ ${ }^{2}$ Neurology Department, Hospital de Especialidades Carlos Andrade Marín, Quito - Ecuador
}

\begin{abstract}
Introduction: Multiple sclerosis is a neurological condition that causes disabilities and is most common in young adults. It imposes high financial costs affecting the quality of life of patients, families, and society. It is critical to measure the budgetary impact of new technologies to treat this disease.

Objective: The aim of the article is to estimate the budgetary impact of introducing alemtuzumab as an escalation therapy in patients diagnosed with Recurrent Remitting Multiple Sclerosis and treated in Quito, Ecuador.

Materials and methods: A cohort of 85 patients receiving treatment with disease-modifying therapies was used, within a 5-year timeframe, between 2021 and 2025. The baseline scenario, including the percentages of administration of the different drugs, is compared with the alternative scenario, including alemtuzumab. The cost assessment included only direct medical resources. To obtain local resources for management of the disease, a neurologist and clinical expert who treats most of the patients in Quito was consulted.

Results: Considering a cohort of 85 patients with active Recurrent Remitting Multiple Sclerosis, the average global budget impact in 5 years would be USD 10,603,230.00 in the base case and USD 9,995,817.00 in the alemtuzumab scenario.

Conclusion: The inclusion of alemtuzumab as escalation therapy represents budgetary savings over the next 5 years (2021-2025).

Keywords: Multiple sclerosis, Interferons, Budgetary impact analysis, Fingolimod, Alemtuzumab, Ocrelizumab, Teriflunomide
\end{abstract}

\section{Introduction}

Multiple sclerosis (MS) is the most common chronic neurological disease in young adults (1) and imposes high financial costs, affecting patients' quality of life, families, and society (2). It is a chronic disorder that can place a significant burden on patients over the years (3). MS affects mostly adult women (4). It most frequently presents as Recurrent Remitting Multiple Sclerosis (RRMS). Approximately $85 \%$ of patients are affected by this form of MS, which is characterized by the occurrence of one or two episodes of neurological

Received: April 27, 2021

Accepted: September 17, 2021

Published online: October 21, 2021

This article include supplementary materials

\section{Corresponding author:}

Dr. Luis J. Pastor-Quirós

Investigador independiente

Residencial Rincón Verde II

Casa 28H, 40902 Heredia - Costa Rica

ljpastor@icloud.com deficit per year, which resolve, at least partially, with or without treatment, in days or months (5).

According to information from the Association of Patients with Multiple Sclerosis and Demyelinating Diseases of Ecuador (APEMEDE), as of June 2020, 124 patients with Active RRMS in Ecuador receive care from the Carlos Andrade Marín Specialty Hospital (HECAM) and the Eugenio Espejo Hospital, which are third-level health centers in the city of Quito, capital of Ecuador.

\section{Definitions used in the model}

Relapse or flare: The appearance of new neurological symptoms or the worsening of existing ones for a period of time longer than 24 hours (6).

Costs: Direct medical costs, which are expressed in US dollars. The costs were obtained from the Consolidated Ceiling Prices Updated 2020-10-02 (7) and the Benefit Tariff for the National Health System Version Year 2014 (8). The costs associated with the monitoring of each therapy and costs related to the management of the adverse events are included in this analysis, as well as those related to outbreaks, according to their severity.

Escalation: Switch to a high-efficacy drug (9). 


\section{Sensitivity analysis}

A series of deterministic univariate sensitivity analyses were performed to verify the robustness of the model results, which evaluated the parameter's impact with the most uncertainty in the analysis, namely, the price of the drug. For this, the economic impact was estimated if $100 \%$ of the patients included in the model were administered only one drug. This analysis was carried out for each of the therapeutic alternatives included in the model.

There is no definitive cure for MS to date; hence, treatment aims at modifying the natural course of the disease. In the last decade, there has been a rapid development in the investigation of new disease-modifying therapies (DMTs) for patients with MS (10).

In recent years, new treatments have emerged to slow the progression of RRMS, both immunomodulatory and immunosuppressive. However, the drugs approved to date only allow the modification of the disease's course, delaying its progression and avoiding relapses. Alemtuzumab emerges as a promising and cost-effective therapy, the reason why it has been considered essential to evaluate its budgetary impact at a local level.

\section{Materials and methods}

A Budget Impact Analysis predicts how a change in the combination of drugs and other therapies used to treat a particular health condition will impact the trajectory of spending on that condition. It can be used for budget planning, forecasting, and calculating the impact of changes in health technology on health insurance premiums. In the present work, the budget impact model was carried out using the Microsoft Excel 2011 program for Mac, following international recommendations (11).

From a population of 124 patients with RRMS, according to the APEMEDE registry, treated in Quito, a target sample of 85 patients was estimated, undergoing treatment with interferon beta 1a (IFN $\beta-1$ a) intramuscular (IM), IFN $\beta-1 a$ subcutaneous (SC), ocrelizumab, teriflunomide $14 \mathrm{mg}$, and fingolimod. The inclusion criteria were RRMS diagnosis in treatment with DMTs, without distinguishing gender, disease status, or age. The exclusion criteria were: patients diagnosed with RRMS under treatment with rituximab (because it was off-label use), natalizumab (there were no patients with this therapy), and those who did not have any DMT. Data was taken from an online query made to APEMEDE.

The study is an adaptation of a budget impact model made for Social Security in Costa Rica (12). The model assumes that there are no transitions between EDSS states throughout the time horizon. The only effect for DMTs included in the model is the number of outbreaks requiring hospitalization or not. In the case of alemtuzumab, the CARE MS II clinical study is used as a reference, a randomized controlled phase III study of alemtuzumab in patients with RRMS previously exposed to another DMT (13). The information is summarized in Table I.

In the base case, a cohort with 85 patients using the following therapies was considered: $(18 ; 85)$ patients with IFN $\beta-1$ a IM, $(41 ; 85)$ patients with IFN $\beta-1$ a SC, $(3 ; 85)$ patients
TABLE I - Budget impact model characteristics

\begin{tabular}{|c|c|}
\hline Summary & Description \\
\hline $\begin{array}{l}\text { Type of economic } \\
\text { analysis }\end{array}$ & Budget impact model \\
\hline Intervention & - Alemtuzumab \\
\hline Comparators & $\begin{array}{l}\text { - Interferon beta-1a intramuscular } \\
\text { - Interferon beta-1a subcutaneous } \\
\text { - Teriflunomide } 14 \mathrm{mg} \\
\text { - Fingolimod } \\
\text { - Ocrelizumab }\end{array}$ \\
\hline Population & $\begin{array}{l}\text { Adults on Recurrent Remitting Multiple } \\
\text { Sclerosis (RRMS) using a disease-modifying } \\
\text { therapy }\end{array}$ \\
\hline Perspective & Payer \\
\hline Time horizon & 5 years \\
\hline Health states & $\begin{array}{l}\text { Transitions between states were not } \\
\text { considered. }\end{array}$ \\
\hline Primary outcome & $\begin{array}{l}\text { Both annual and } 5 \text {-year cost for the } \\
\text { population with RRMS }\end{array}$ \\
\hline Assumptions & $\begin{array}{l}\text { - Patients do not switch treatment } \\
\text { throughout the time horizon. } \\
\text { - The effect of the considered treatment is } \\
\text { the reduction of the relapse rate only. } \\
\text { - Transfers to Progressive Secondary } \\
\text { Multiple Sclerosis (SPMS) are not possible } \\
\text { throughout the time horizon. }\end{array}$ \\
\hline
\end{tabular}

Source: Authors' research database.

with teriflunomide $14 \mathrm{mg}$ orally, $(21 ; 85)$ patients with fingolimod tablets, and $(2 ; 85)$ patients with ocrelizumab, in correspondence with the real data as of July 2020.

In the alternative scenario with alemtuzumab, the same cohort of 85 patients was considered, but with $(10 ; 85)$ patients using alemtuzumab; $(5 ; 85)$ patients move from the pool of patients using IFN $\beta-1$ a SC and $(5 ; 85)$ patients from those using fingolimod (Tab. II).

\section{Therapeutic alternatives}

The therapeutic alternatives evaluated in the analysis included the following drugs, which are used in Quito for the treatment of active RRMS:

\section{First line}

IFN $\beta$-1a IM

IFN $\beta$-1a SC

Terifllunomide $14 \mathrm{mg}$ coated tablets

\section{Second line}

Fingolimod $0.5 \mathrm{mg}$ hard capsule

Ocrelizumab concentrate for solution for infusion

For modeling purposes, a reference or base case scenario was used, in which the percentages of use of each of the 
TABLE II - Distribution of the cohort of patients with relapsing remitting multiple sclerosis, diagnosed and treated in Quito, Ecuador

\begin{tabular}{|c|c|c|c|c|c|c|c|c|c|c|c|c|c|}
\hline \multirow[t]{2}{*}{ PRODUCT } & & \multicolumn{2}{|c|}{2020} & \multicolumn{2}{|c|}{2021} & \multicolumn{2}{|c|}{2022} & \multicolumn{2}{|c|}{2023} & \multicolumn{2}{|c|}{2024} & \multicolumn{2}{|c|}{2025} \\
\hline & & No. & $\%$ & No. & $\%$ & No. & $\%$ & No. & $\%$ & No. & $\%$ & No. & $\%$ \\
\hline \multirow{7}{*}{$\begin{array}{l}\text { BASE CASE } \\
\text { (without } \\
\text { alemtuzumab) }\end{array}$} & IFNB-1a IM & 18 & 21.18 & 18 & 21.18 & 18 & 21.18 & 18 & 21.18 & 18 & 21.18 & 18 & 21.18 \\
\hline & IFNB-1a SC & 41 & 48.24 & 41 & 48.24 & 41 & 48.24 & 41 & 48.24 & 41 & 48.24 & 41 & 48.24 \\
\hline & $\begin{array}{l}\text { Teriflunomide } \\
14 \text { mg tab. }\end{array}$ & 3 & 3.53 & 3 & 3.53 & 3 & 3.53 & 3 & 3.53 & 3 & 3.53 & 3 & 3.53 \\
\hline & Fingolimod & 21 & 24.71 & 21 & 24.71 & 21 & 24.71 & 21 & 24.71 & 21 & 24.71 & 21 & 24.71 \\
\hline & Natalizumab & 0 & 0.00 & 0 & 0.00 & 0 & 0.00 & 0 & 0.00 & 0 & 0.00 & 0 & 0.00 \\
\hline & Ocrelizumab & 2 & 2.35 & 2 & 2.35 & 2 & 2.35 & 2 & 2.35 & 2 & 2.35 & 2 & 2.35 \\
\hline & Total & 85 & 100.00 & 85 & 100.00 & 85 & 100.00 & 85 & 100.00 & 85 & 100.00 & 85 & 100.00 \\
\hline \multirow{13}{*}{$\begin{array}{l}\text { ALTERNATIVE } \\
\text { CASE (with } \\
\text { alemtuzumab) }\end{array}$} & IFNB-1a IM & 18 & 21.18 & 18 & 21.18 & 18 & 21.18 & 18 & 21.18 & 18 & 21.18 & 18 & 21.18 \\
\hline & IFNB-1a SC & 41 & 48.24 & 36 & 42.35 & 36 & 42.35 & 36 & 42.35 & 36 & 42.35 & 36 & 42.35 \\
\hline & $\begin{array}{l}\text { Teriflunomide } \\
14 \mathrm{mg} \text { tab. }\end{array}$ & 3 & 3.53 & 3 & 3.53 & 3 & 3.53 & 3 & 3.53 & 3 & 3.53 & 3 & 3.53 \\
\hline & Fingolimod & 21 & 24.71 & 16 & 18.82 & 16 & 18.82 & 16 & 18.82 & 16 & 18.82 & 16 & 18.82 \\
\hline & Natalizumab & 0 & 0.00 & 0 & 0.00 & 0 & 0.00 & 0 & 0.00 & 0 & 0.00 & 0 & 0.00 \\
\hline & Ocrelizumab & 2 & 2.35 & 2 & 2.35 & 2 & 2.35 & 2 & 2.35 & 2 & 2.35 & 2 & 2.35 \\
\hline & Alemtuzumab course 1 & 0 & 0.00 & 10 & 11.76 & 0 & 0.00 & 0 & 0.00 & 0 & 0.00 & 0 & 0.00 \\
\hline & Alemtuzumab course 2 & & & & & 10 & 11.76 & 0 & 0.00 & 0 & 0.00 & 0 & 0.00 \\
\hline & Alemtuzumab course 3 & & & & & & & 2 & 2.35 & 0 & 0.00 & 0 & 0.00 \\
\hline & Alemtuzumab course 4 & & & & & & & & & 2 & 2.35 & 0 & 0.00 \\
\hline & Alemtuzumab course 5 & & & & & & & & & & & 1 & 1.18 \\
\hline & Free of therapy & & & & & & & 8 & 9.41 & 8 & 9.41 & 9 & 10.59 \\
\hline & Total & 85 & 100.00 & 85 & 100.00 & 85 & 100.00 & 85 & 100.00 & 85 & 100.00 & 85 & 100.00 \\
\hline
\end{tabular}

IFNB-1a IM = interferon beta 1a intramuscular; IFNB-1a SC = interferon beta 1a subcutaneous.

Source: Association of Patients with Multiple Sclerosis and Demyelinating Diseases of Ecuador (APEMEDE) (with permission).

drugs indicated in the first line and second line for the treatment of patients with active RRMS were included. This base case was compared with a scenario that recreates alemtuzumab's use in $11.76 \%)$ of the cohort $(10 ; 85)$ patients, varying the participation percentages of the different treatments currently used. In this way, the incremental cost of the inclusion of alemtuzumab can be calculated.

\section{Time horizon, perspective, and discount rate}

The analysis was carried out with a time horizon of 5 years, according to the payer's perspective. A discount rate was not be applied due to the limitation, for this work, of obtaining the most appropriate indicator in the health area.

\section{Resources}

The analysis has been carried out following the payer's perspective. Only resources related to direct healthcare costs were considered, which are those financed by the health authorities.

\section{Drugs and acquisition costs, for each DMT}

\section{Treatment administration}

The model assumed that the administration of intravenous therapies is performed by qualified personnel; therefore, intravenous administration is associated with an outpatient visit or hospitalization, depending on the type of therapy. Subcutaneous therapy (Interferons) and oral therapies can be self-administered by the patient.

\section{Management of the disease}

The information about the disease's management was obtained from a local expert and the available clinical evidence.

\section{Adverse events}

The most frequent and severe adverse events of each of the products were selected according to the pivotal studies 
published for each therapy (14-18). Regarding its clinical management, only the clinician's medications for its management and the consultation with the respective service (either the emergency department or the neurology specialist) were considered.

\section{Outbreaks and annualized relapse rate}

Annualized relapse rates are based on clinical evidence for each of the products (pivotal studies). For management of outbreaks, the information was collected through a local expert.

\section{Quantification of resources}

The estimation and quantification of the resources used are summarized in the tables included in the supplementary materials (Tabs. IV-VII).

\section{Results}

Table III shows the total economic impact, broken down into pharmacological, administration, and monitoring costs. The budgetary impact for the cohort of patients with active RRMS in treatment at the Carlos Andrade Marín Hospital,

TABLE III - Model results

\begin{tabular}{|c|c|c|c|c|c|}
\hline Total cost per year for each scenario & 2021 & 2022 & 2023 & 2024 & 2025 \\
\hline Without alemtuzumab & $\$ 2,120,646$ & $\$ 2,120,646$ & $\$ 2,120,646$ & $\$ 2,120,646$ & $\$ 2,120,646$ \\
\hline With alemtuzumab & $\$ 2,418,917$ & $\$ 2,159,217$ & $\$ 1,812,638$ & $\$ 1,807,819$ & $\$ 1,797,226$ \\
\hline \multicolumn{6}{|c|}{ Annual costs breakdown: drugs, administration, monitoring, adverse events, relapse cost } \\
\hline Drug cost & 2021 & 2022 & 2023 & 2024 & 2025 \\
\hline Difference & $\$ 281,477$ & $\$ 30,719$ & $-\$ 301,642$ & $-\$ 306,052$ & $-\$ 315,335$ \\
\hline Drug administration & 2021 & 2022 & 2023 & 2024 & 2025 \\
\hline Without alemtuzumab & $\$ 1,015$ & $\$ 1,015$ & $\$ 1,015$ & $\$ 1,015$ & $\$ 1,015$ \\
\hline With alemtuzumab & $\$ 12,321$ & $\$ 7,580$ & $\$ 1,296$ & $\$ 1,212$ & $\$ 1,037$ \\
\hline With alemtuzumab & $\$ 39,618$ & $\$ 35,417$ & $\$ 31,268$ & $\$ 31,097$ & $\$ 30,504$ \\
\hline Difference & $\$ 5,347$ & $\$ 1,146$ & $-\$ 3,003$ & $-\$ 3,174$ & $-\$ 3,767$ \\
\hline Adverse event cost & 2021 & 2022 & 2023 & 2024 & 2025 \\
\hline Without alemtuzumab & $\$ 1,139$ & $\$ 1,139$ & $\$ 1,139$ & $\$ 1,139$ & $\$ 1,139$ \\
\hline With alemtuzumab & $\$ 1,379$ & $\$ 1,379$ & $\$ 1,121$ & $\$ 1,110$ & $\$ 1,073$ \\
\hline Difference & $\$ 240$ & $\$ 240$ & $-\$ 18$ & $-\$ 28$ & $-\$ 65$ \\
\hline Relapse cost & 2021 & 2022 & 2023 & 2024 & 2025 \\
\hline Without alemtuzumab & $\$ 44,065$ & $\$ 44,065$ & $\$ 44,065$ & $\$ 44,065$ & $\$ 44,065$ \\
\hline With alemtuzumab & $\$ 43,967$ & $\$ 43,967$ & $\$ 40,440$ & $\$ 40,295$ & $\$ 39,791$ \\
\hline Difference & $\$ 16,875$ & $\$ 7,933$ & $-\$ 3,393$ & $-\$ 3,683$ & $-\$ 4,580$ \\
\hline Pharmacy costs & 2021 & 2022 & 2023 & 2024 & 2025 \\
\hline Without alemtuzumab & $\$ 2,076,292$ & $\$ 2,076,292$ & $\$ 2,076,292$ & $\$ 2,076,292$ & $\$ 2,076,292$ \\
\hline With alemtuzumab & $\$ 2,357,688$ & $\$ 2,106,930$ & $\$ 1,771,677$ & $\$ 1,767,148$ & $\$ 1,757,452$ \\
\hline Difference & $\$ 281,396$ & $\$ 30,638$ & $-\$ 304,615$ & $-\$ 309,144$ & $-\$ 318,840$ \\
\hline
\end{tabular}

Source: Authors' research database. 

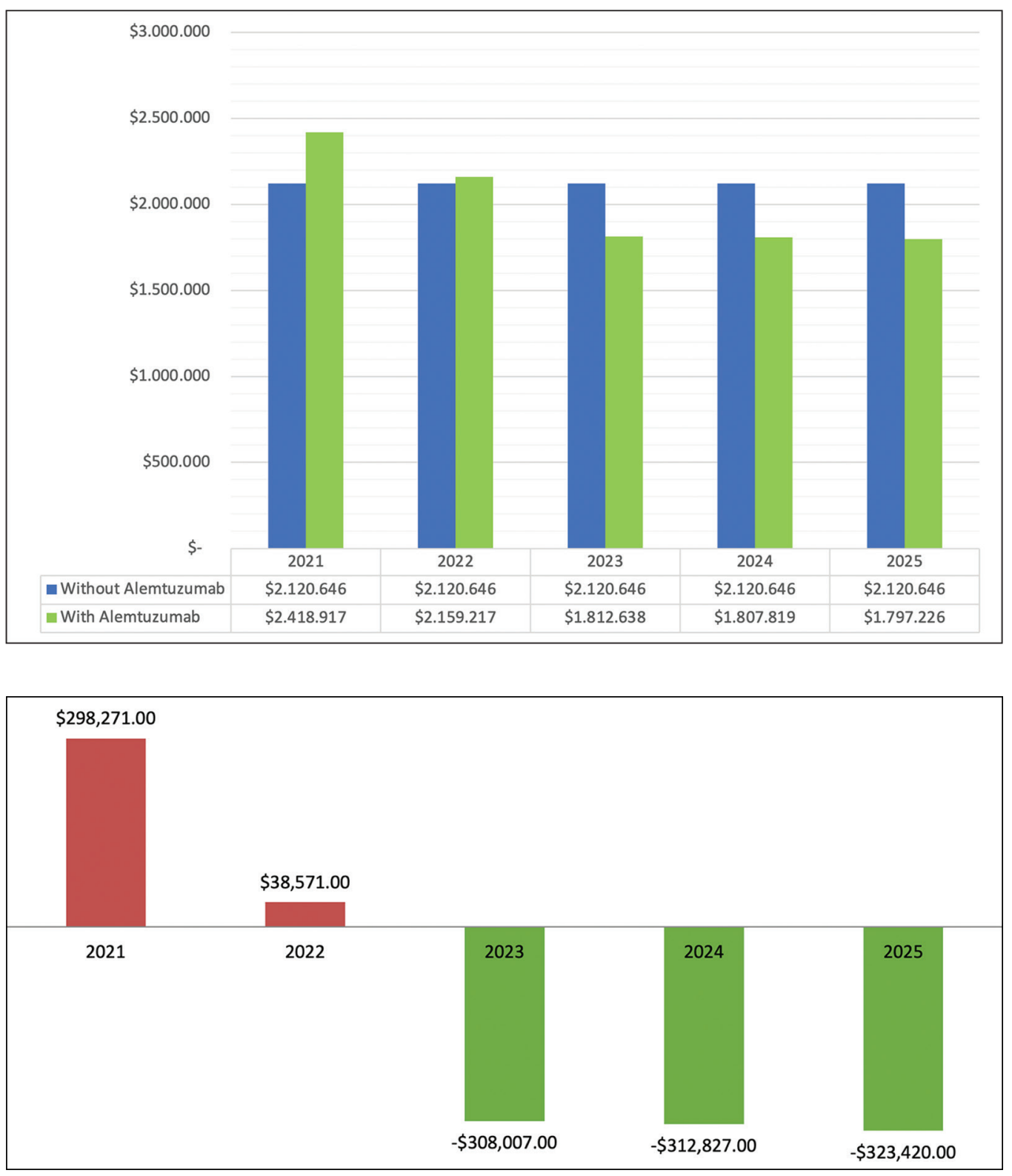

Fig. 1 - Budget impact in base case and alternative case.
Fig. 2 - Budgetary impact of the inclusion of alemtuzumab. in the base case, represents a 5 -year investment of USD $10,603,230.00$ and USD 9,995,817.00 in the alternative scenario with alemtuzumab. The alternative scenario, which includes $11.76 \%$ of new patients with alemtuzumab $(10 ; 85)$, reduces the investment by $5.73 \%$ of the total at 5 years, representing an average saving of USD 7,146.00 per patient in 5 years.

Figure 1 shows the budgetary impact by year and an annual decreasing trend is observed in the budgetary impact in the scenario with alemtuzumab, starting the third year.

Figure 2 shows the delta between both scenarios, with a clear impact in favor of the alemtuzumab scenario from year 2 . Figure 3 shows the average monthly average cost per year and patient, observing a lower cost in the scenario with alemtuzumab, from the second year of the time horizon.

\section{Sensitivity analysis}

Figure 3 shows the budgetary impact in 5 years, with regard to univariate parameter modifications. The pharmacological cost is the parameter with the most significant weight in the analysis. A sensitivity analysis was made based on the hypothetical scenario using each drug in $100 \%$ of the patients in the cohort, that is, $(85 ; 85)$ patients. It is observed that, according to the drug under analysis, the budgetary impact is within a range that increases or decreases investment. This analysis reflects that alemtuzumab constitutes an escalation therapy, positively impacting the payer's budget.

\section{Discussion and limitations}

The analysis of the budgetary impact of introducing new drugs in the treatment of MS could optimize existing 


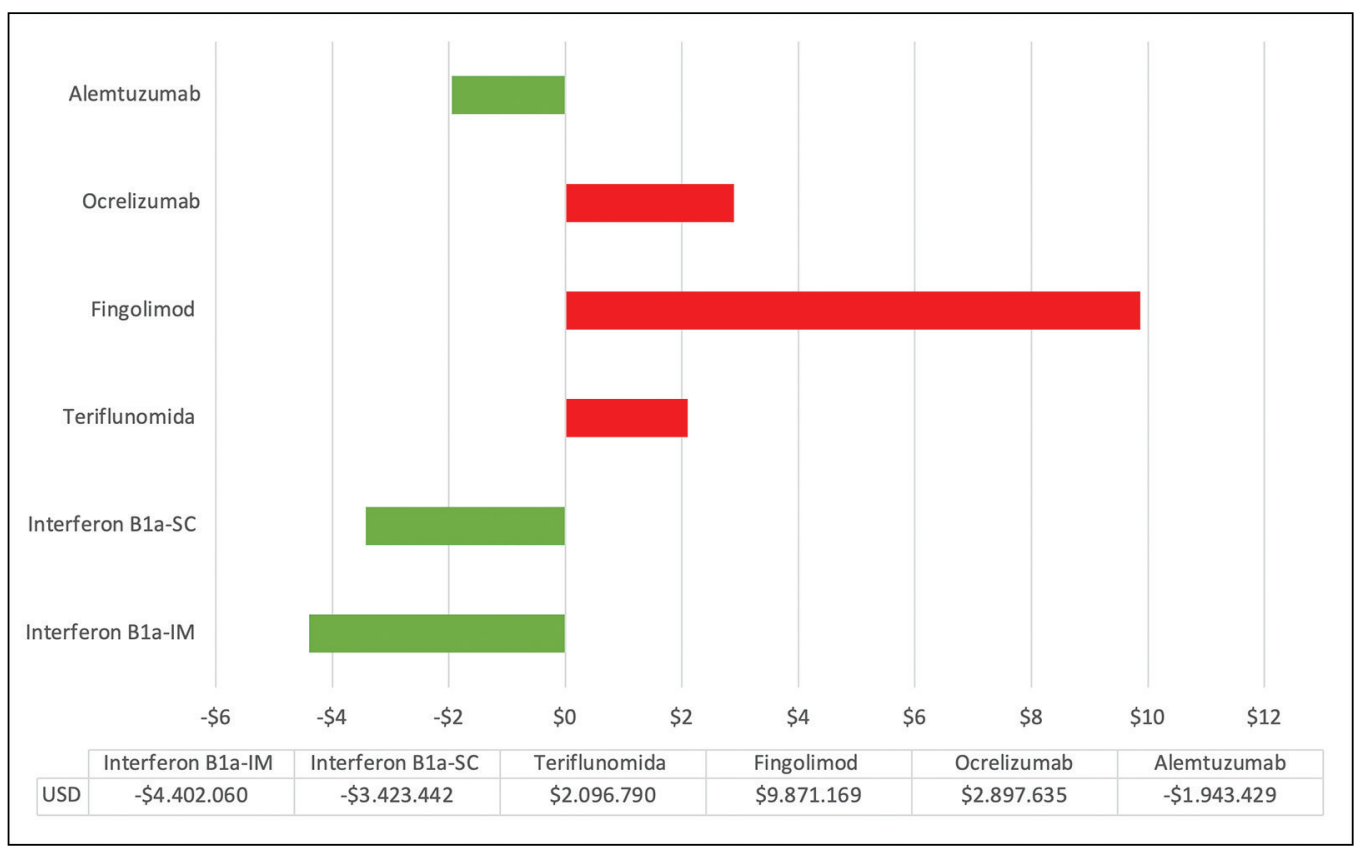

Fig. 3 - Budgetary impact (millions of USD) in a hypothetical case of $100 \%$ of patients (85; $85)$ with each therapy through 5 years.

economic resources. In Ecuador, there are no studies of this nature to date.

Although there is consensus that DMTs can reduce the frequency of relapses, their relative benefit (effectiveness compared to each other) in reducing new relapses or the progression of disability remains unclear due to the limited number of studies with direct comparisons. However, to assess the relative efficacy of the alternatives among themselves, in terms of annualized relapse rate, indirect comparisons can be used, obtained by a Cochrane network meta-analysis carried out in 2015 (19). The network meta-analysis showed that, in terms of the protective effect against relapse recurrence in RRMS, during the first 24 months of treatment, alemtuzumab, natalizumab, and fingolimod outperformed other drugs.

Given the nature of MS, these therapies are chronic in use, representing a significant investment for payers. On the other hand, the economic burden of managing MS is very high. The objective of this study was to estimate the budgetary impact of the inclusion of alemtuzumab, as escalation therapy, in the population with active RRMS.

For first-line treatment of the disease in Quito, beta interferons are available: IFN $\beta-1$ a IM and IFN $\beta-1$ a SC. Some patients use teriflunomide and fingolimod.

The information collected by APEMEDE (see Supplementary Materials) indicates that, as of June 2020, there were 3 patients with alemtuzumab, 21 patients with fingolimod, 18 patients with IFN $\beta-1$ a IM, 41 patients with IFN $\beta-1$ - SC, 3 patients with teriflunomide, 2 patients with ocrelizumab, 34 patients with rituximab (off-label use) and 2 patients without DMT.

\section{Important note}

At the date of the study, there were no patients treated with other DMTs, for example, natalizumab. Under the above, natalizumab was excluded from the study as it is not locally used. Rituximab was also excluded as it is used off-label, and this does not allow a fair and referenced comparison with the other DMTs with approved indications to treat the disease under review.

According to the payer's perspective, this partial economic model provides data on the budgetary impact for local public payers of the management of active RRMS. The inclusion of alemtuzumab to treat 10 of the 85 patients represents a saving of $8.9 \%$ of the 5 -year budget, compared to the base case budget (current situation), as long as alemtuzumab meets the efficacy and decreasing retreatment rates, evidenced in the pivotal CARE MS II study. The parameter with the most significant influence on the results is the pharmacological cost, which should encourage further discussions on this specific topic.

Within the limitations, it is found that this model considers only the direct costs for the system and does not consider the social impact of MS and the economic impact of disease progression in the long term, which may justify additional studies. On the other hand, the absence of a national registry of the disease makes it necessary to assume that the results of clinical trials can be extrapolated in Ecuador, especially regarding the incidence rates of adverse events.

Another limitation is that the model does not include the impact of health states (expanded disability status scale, EDSS). According to the number of patients, there is no consolidated information published regarding the distribution percentage in each state.

On the other hand, although the collection of unit costs was accurate (considering that it is obtained from direct sources from the Ecuadorian Institute of Social Security and the Ministry of Health), some few costs could not be determined, resulting in the use of values corresponding to the private market.

There is no Local Clinical Practice Guide, so access to information on management of the disease was carried out in consultation of an expert. 


\section{Conclusion}

Under the assumptions presented in this work, it can be concluded that, from the payer's perspective, the introduction of alemtuzumab, as escalation therapy, represents budgetary savings over a 5-year time horizon. Greater benefits in reducing the retreatment rate and a very manageable shortterm dosing regimen in most patients make it possible to recommend, both clinical and economically, the rational and progressive use of the product in this context.

\section{Recommendations}

Additional studies are recommended, including the progression of the disease in the cohort, to obtain a dynamic model. It is recommended to expand this work with additional studies, as new DMTs are included in providing services.

\section{Acknowledgments}

To Dr. Mario Tristán, PhD, general director and CEO, IHCAI foundation, and director of Cochrane Central America and the Spanish-speaking Caribbean, who contributed as an advisor in evidence-based medicine for this work.

Asociación de Pacientes con Esclerosis Múltiple y Enfermedades Desmielinizantes de Ecuador (APEMEDE). This Association contributed with the approval of the preliminary project and the provision of data to carry out this study.

\section{Disclosures}

Funding/support: This study was carried out by Luis Pastor and Patricio Correa with their own funds, without financial help from any company or third party.

Financial disclosure: None.

\section{References}

1. Fernández O, Fernández VE, Guerrero M. Esclerosis múltiple. Medicine (Spain). 2015;77:4610-4621. CrossRef

2. FAGUY K. Multiple sclerosis: an update. Radiol - Google Académico. Online, accessed July 16, 2020.

3. Maia C, Costa A, Abreu P, Sá MJ. All-cause hospitalizations in multiple sclerosis patients. Rev Neurol. 2019;68(6):229-235. CrossRef PubMed
4. Bravo-González F, Álvarez-Roldán A. [Multiple sclerosis, loss of functionality and gender]. Gac Sanit. 2019;33(2):177-184. CrossRef PubMed

5. Moreno RD, Morales Esponda M, Lorena N, et al. Esclerosis Múltiple: Revisión de La Literatura Médica.

6. Delgado FR, Margarit BP, Monteiro GC, Izquierdo AY. Diagnostic and therapeutic protocol for multiple sclerosis flare-ups. Medicine (Spain). 2019;12(78):4630-4633. CrossRef

7. Consolidado precios techo actualizado 2018-10-02 - Ministerio de Salud Pública. Online, accessed July 16, 2020.

8. MSP. Gobierno de la República del Ecuador. Ministerio de Salud Pública. Tarifario de Prestaciones para el Sistema Nacional de Salud 2014. Online, accessed July 16, 2020.

9. Huamaní C, Rojas E, Inca J. Esclerosis múltiple de alta actividad: ¿se puede iniciar precozmente el tratamiento con drogas de alta eficacia? Acta Med Peru. 2017;34(4):301-8. Online, accessed July 16, 2020.

10. Vizcarra DR, Cruz AG, Rojas E, et al. Guía de Práctica Clínica para el Diagnóstico y Tratamiento de Esclerosis Múltiple en Adultos. Rev Neuropsiquiatr. 2019;82(4):242-257. CrossRef

11. Sullivan SD, Mauskopf JA, Augustovski F, et al. Budget impact analysis-principles of good practice: report of the ISPOR 2012 Budget Impact Analysis Good Practice II Task Force. Value Health. 2014;17(1):5-14. CrossRef PubMed

12. Pastor Quirós L, Ugalde R. Análisis del impacto presupuestario de alemtuzumab como terapia de segunda línea, en comparación con natalizumab y fingolimod, en pacientes previamente tratados con interferón beta $1 b$, diagnosticados con esclerosis múltiple remitente recurrente activa, Glob Reg Health Technol Assess. 2019:6(1). CrossRef

13. Coles AJ, Twyman CL, Arnolod DL, et al. Alemtuzumab for patients with relapsing multiple sclerosis after disease-modifying therapy: a randomised controlled phase 3 trial. The Lancet 2012;380:1829-1839. CrossRef PubMed

14. EMA. Ocrevus. Annex I Summary of Product Characteristics. Online, accessed July 16, 2020.

15. EMA. Avonex. Annex I Summary of Product Characteristics. Online, accessed July 16, 2020.

16. EMA. Gilenya. Annex I Summary of Product Characteristics. Online, accessed July 16, 2020.

17. EMA. Aubagio. Annex I Summary of Product Characteristics. Online, accessed July 16, 2020.

18. EMA. Rebif. Annex I Summary of Product Characteristics. Online, accessed July 16, 2020.

19. Tramacere I, Del Giovane C, Salanti G, D'Amico R, Filippini G. Immunomodulators and immunosuppressants for relapsingremitting multiple sclerosis: a network meta-analysis. Cochrane Database Syst Rev. 2015(9):CD011381. CrossRef PubMed 